\title{
Transgenic Mice Lacking Serotonin Neurons Have Severe Apnea and High Mortality during Development
}

\author{
Matthew R. Hodges, ${ }^{1}$ Mackenzie Wehner, ${ }^{1}$ Jason Aungst,$^{2}$ Jeffrey C. Smith, ${ }^{2}$ and George B. Richerson ${ }^{1,3}$ \\ ${ }^{1}$ Departments of Neurology and Cellular and Molecular Physiology, Yale University School of Medicine, New Haven, Connecticut 06510, ${ }^{2}$ Cellular and \\ Systems Neurobiology Section, National Institute of Neurological Disorders and Stroke-National Institutes of Health, Bethesda, Maryland 20892-2540, \\ and ${ }^{3}$ Veterans Affairs Medical Center, West Haven, Connecticut 06516
}

Central serotonin (5-HT) neurons modulate many vital brain functions, including respiratory control. Whether breathing depends critically on 5-HT neurons, or whether their influence is excitatory or inhibitory, remains controversial. Here we show that neonatal $L m x 1 b^{\text {floxfflox;ePet-Cre/+ }}$ mice (also called $L m x 1 b^{f f / p}$ mice), which selectively lack serotonin neurons, display frequent and severe apnea lasting as long as $55 \mathrm{~s}$. This was associated with a marked decrease in ventilation to less than one-half of normal. These respiratory abnormalities were most severe during the postnatal period, markedly improving by the time the pups were 2- 4 weeks old. Despite the severe breathing dysfunction, many of these mice survived, but there was a high perinatal mortality, and those that survived had a decrease in growth rate until the age at which the respiratory defects resolved. Consistent with these in vivo observations, respiratory output was markedly reduced in isolated brainstem-spinal cord preparations from neonatal $L m x 1 b^{f f / p}$ mice and completely blocked in perfused brain preparations from neonatal rats treated with selective antagonists of 5- $\mathrm{HT}_{2 \mathrm{~A}}$ and neurokinin 1 (NK-1) receptors. The ventilatory deficits in neonatal $L m x 1 b^{f f / p}$ mice were reversed in vitro and in vivo with agonists of 5- $\mathrm{HT}_{2 \mathrm{~A}}$ and/or NK-1 receptors. These results demonstrate that ventilatory output in the neonatal period is critically dependent on serotonin neurons, which provide excitatory drive to the respiratory network via $5-\mathrm{HT}_{2 \mathrm{~A}}$ and $\mathrm{NK}-1$ receptor activation. These findings provide insight into the mechanisms of sudden infant death syndrome, which has been associated with abnormalities of 5-HT neurons and of cardiorespiratory control.

\section{Introduction}

Breathing is a spontaneous, rhythmic motor output critical for maintaining $\mathrm{O}_{2}, \mathrm{CO}_{2}$, and $\mathrm{pH}$ homeostasis. Serotonin (5-HT) neurons are embedded within the brainstem respiratory network and are thought to play diverse roles, including providing tonic modulatory input to the respiratory network and as $\mathrm{CO}_{2} / \mathrm{pH}$ chemoreceptors (Richerson, 2004; Corcoran et al., 2009; Ptak et al., 2009). However, there remains debate about whether 5-HT neurons are required for the generation and/or stability of breathing and whether their influence is excitatory or inhibitory (Hodges and Richerson, 2008).

Data from rhythmically active slice preparations (Smith et al., 1991) point to a critical role of 5-HT and the cotransmitter substance P (SP). Raphé obscurus 5-HT neurons project directly to the rhythm-generating pre-Bötzinger complex and respiratory motor neurons (Ptak et al., 2009). Within slices, respiratory motor output is blocked with antagonists of 5-HT and/or neurokinin 1 (NK-1) receptors (Pena and Ramirez, 2002; Telgkamp et

\footnotetext{
Received April 24, 2009; revised July 6, 2009; accepted July 8, 2009.

This work was supported by the Parker B. Francis Foundation (M.R.H.), the National Institute of Child Health and Human Development, the Bumpus Foundation, and Veterans Affairs Medical Center (G.B.R.) and the Intramural Research Program of the National Institute of Neurological Disorders and Stroke-National Institutes of Health (J.A. and J.C.S.).

The authors declare no competing financial interests.

Correspondence should be addressed to Dr. Matthew R. Hodges, Department of Neurology, LCI 704, Yale University School of Medicine, New Haven, CT 06520. E-mail: matthew.hodges@yale.edu. DOI:10.1523/JNEUROSCI.1963-09.2009

Copyright $\odot 2009$ Society for Neuroscience $\quad$ 0270-6474/09/2910341-09\$15.00/0
}

al., 2002; Gunther et al., 2006; Ptak et al., 2009), and stimulation of the raphé obscurus increases respiratory burst frequency (Al-Zubaidy et al., 1996; Ptak et al., 2009).

In contrast, the role of 5-HT neurons in the intact nervous system is less clear. For example, eupneic respiratory output in juvenile in situ perfused brain preparations is not prevented by antagonists of 5-HT receptors (Toppin et al., 2007), and 5-HT receptor antagonists do not inhibit breathing in adults in vivo (Ling et al., 2001; McGuire et al., 2004). Blocking 5-HT synthesis in vivo can cause an increase in ventilation $\left(\mathrm{V}_{\mathrm{E}}\right)$, suggesting $5-\mathrm{HT}$ neurons may inhibit breathing (Olson et al., 1979). A possible explanation for these contradictory results is that it is necessary to block the effects of coreleased neuropeptides, in addition to 5 -HT, to significantly reduce excitability of the respiratory network. Consistent with this, a combination of 5-HT and NK-1 receptor antagonists eliminates respiratory output in juvenile in situ perfused brain preparations (Ptak et al., 2009). Similar experiments have not yet been performed in vivo.

Lesions of 5-HT neurons with toxins such as 5,7-dihydroxytryptamine (Mueller et al., 1984; Cummings et al., 2009), or antiSERT (serotonin transporter)-saporin (Nattie et al., 2004) have inconsistent effects on baseline ventilation, possibly because of a variable percentage of remaining 5-HT neurons. Pet-1 knock-out mice have only $30 \%$ of the normal number of 5-HT neurons but display only mildly disrupted breathing as neonates (Erickson et al., 2007). Knock-out of the transcription factor Lmx1b in Pet-1expressing neurons $\left[L m \times 1 b^{\text {flox/flox;ePet-Cre/+ }}\left(L m \times 1 b^{f / f / p}\right)\right]$ specifically eliminates all 5-HT neurons (Zhao et al., 2006). As adults, 
these mice have a decreased ventilatory response to hypercapnia and reduced baseline respiratory frequency but only a small and inconsistent reduction in baseline ventilation (Hodges and Richerson, 2008; Hodges et al., 2008). Together, these data have been interpreted by some as indicating that there is little if any stimulation of baseline breathing by 5-HT neurons in vivo.

Here we study neonatal $L m \times 1 b^{f f / p}$ mice and demonstrate a critical excitatory influence of 5-HT neurons on breathing in vivo and in vitro mediated by $5-\mathrm{HT}_{2 \mathrm{~A}}$ and NK-1 receptor agonists. This dependence on 5-HT neurons is lost as these mice develop into adults.

\section{Materials and Methods}

All procedures and protocols were approved by the Yale Animal Care and Use Committee or by the National Institute of Neurological Disorders and Stroke Animal Care and Use Committee before study.

Animal model. Generation of $\operatorname{Lm} x \mathrm{l} b^{\mathrm{ff} f / p}$ mice has been previously described (Zhao et al., 2006). Females that were homozygous for floxed Lmxlb $\left(\operatorname{Lm} \times 1 b^{f / f}\right)$ were bred with male mice that were homozygous for floxed $L m x 1 b$ and hemizygous for ePet1-Cre (Lmx $\left.1 b^{\text {flox/flox;ePet-Cre/+ }}\right)$ to generate progeny of these two genotypes in a 1:1 ratio. Lmx $1 b^{\text {flox/flox;ePet-Cre/+ }}$ mice, also referred to as $L m \times 1 b^{f f f / p}$ mice, fail to develop central 5-HT neurons, whereas $L m x 1 b^{f / f}$ mice are phenotypically normal and have a normal complement of 5-HT neurons [referred to here as wild type (WT)]. Tail biopsy samples were obtained on or before the fourth postnatal day of life (P4) for genotyping, using procedures previously described (Zhao et al., 2006).

Ventilatory measurements. Ventilation was measured in vivo using whole-body plethysmography with methods similar to those described previously (Hodges and Richerson, 2008; Hodges et al., 2008). Two complementary approaches were used: (1) flow-through and (2) stop-flow. Both approaches allow ventilatory measurements from unrestrained mice, so that resting breathing was unperturbed, allowing accurate measurements of frequency and apneas. Stop-flow plethysmography has the advantage that it allows lownoise recordings of small-amplitude breaths in very young neonatal mice. This approach was used for all of the apnea studies (from P2 to P20) so that small breaths were not missed and mistakenly categorized as apnea. This approach does not allow calculation of actual tidal volumes, so tidal volume and ventilation were expressed relative to WT values. Flow-through plethysmography was used to study a separate subgroup of mice aged P2-P28, including some that were older than P12 in which temperature probes were implanted to allow tidal volumes and minute ventilation to be calculated. This approach has the added advantage of allowing measurements of oxygen consumption $\left(\mathrm{VO}_{2}\right)$, thus permitting normalization of ventilation to metabolic rate.

Baseline ventilation was measured in two sets of WT and $L m x 1 b^{f / f / p}$ mice at ages from P2 to P28 in plethysmographs of different volumes (9 $\mathrm{ml}, 15 \mathrm{ml}$, and $28 \mathrm{ml}$ ), to maximize the ventilation signal and allow for growth. As described previously (Hodges and Richerson, 2008; Hodges et
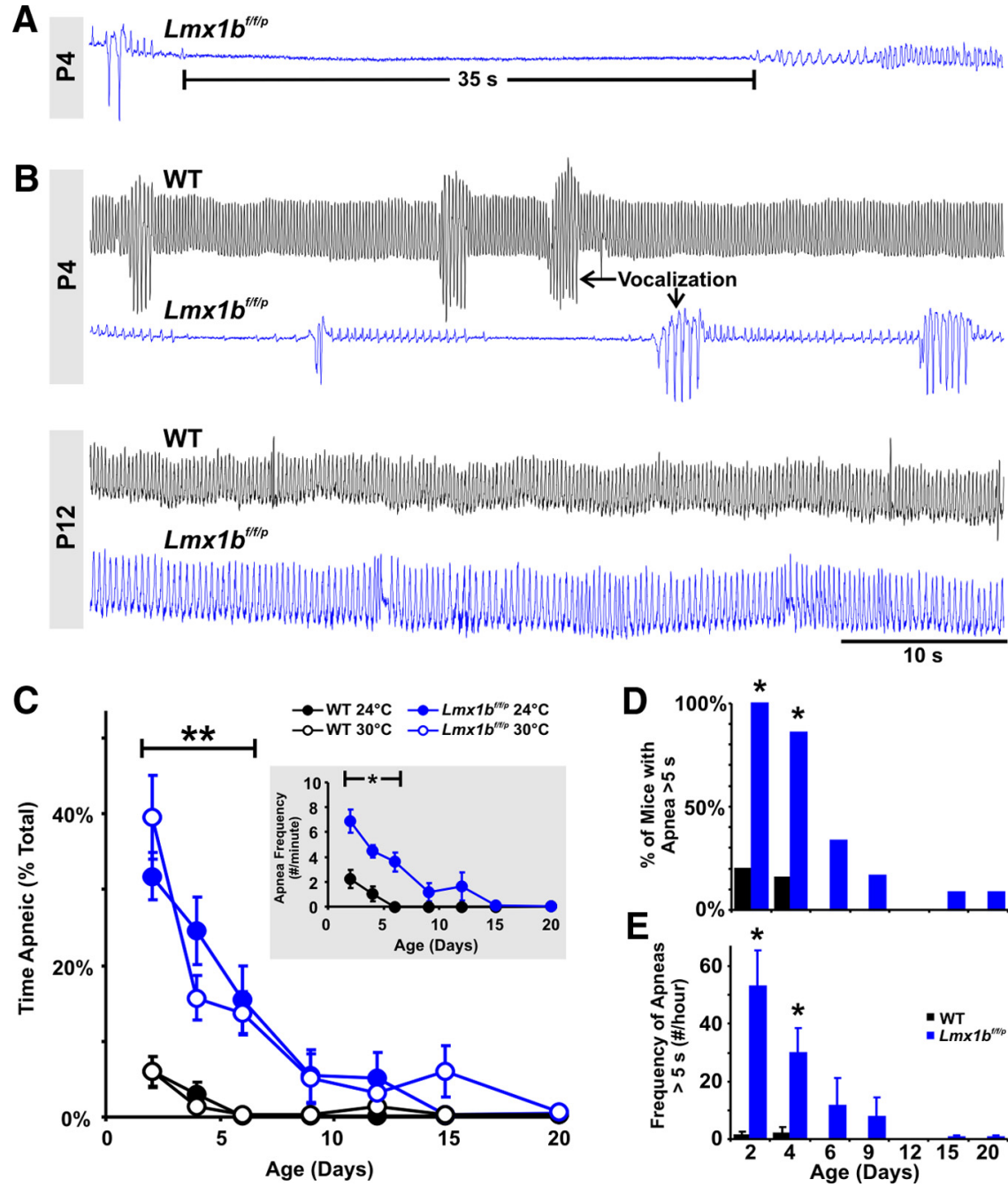

Figure 1. Mice lacking 5-HT neurons have severe and frequent apnea during early development, which resolves with maturation. A, Plethysmography recording from a P4 $L m \times 1 b^{f / f / p}$ mouse with a prolonged (35 s) apnea and erratic low-amplitude breaths (raw trace; inspiration is an upward deflection, and expiration is downward). $\boldsymbol{B}$, Recordings from two P4 mice (upper traces). The WT mouse (black trace) had continuous, rhythmic breathing, whereas the $L m \times 1 b^{f / f / p}$ mouse (blue trace) had short periods of

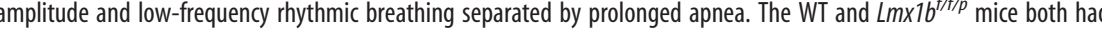
episodes of vocalization (arrows) that were equivalent in amplitude (after normalization to weight; see Results), demonstrating that $L m \times 1 b^{f / f / p}$ mice were capable of large-amplitude inspiratory efforts and that these could be accurately measured. Recording from the same two mice at P12 (lower traces) show marked improvement of the $L m \times 1 b^{f f / p}$ mouse, with regular breathing and no apnea. $C$, Changes in apnea with age in WT (black; $n=13$ ) and $L m \times 1 b^{f f / p}$ (blue; $\left.n=14\right)$ mice. $L m \times 1 b^{f f / p}$ mice spent more time apneic (total apnea duration as a percentage of total study time, measured at ambient temperatures of 24 and $30^{\circ} \mathrm{C}$; ${ }^{* *} p \leq 0.013$ ), and had a greater apnea frequency [inset $\left(24^{\circ} \mathrm{C}\right)$ ], up to the age of $\mathrm{Pg}\left({ }^{*} p \leq 0.001\right)$. D. The percentage of $L m \times 1 b^{f / f / p}$ (blue) mice with prolonged ( $>5 \mathrm{~s}$ ) apnea was greater $\left({ }^{*} p<0.006 ; \chi^{2}\right.$ with Yates correction) relative to WT mice (black) at the ages of P2 and $\mathrm{P4}$, and this declined with postnatal development. $\boldsymbol{E}$, The frequency of prolonged apneas was also greater $\left({ }^{*} p<0.001\right)$ in $\operatorname{Lm} \times 1 b^{f / f / p}$ mice at these same ages.

al., 2008), each chamber had ports for gas inflow and outflow, a pressure transducer, and a relative humidity and ambient temperature sensor. During flow-through experiments, tidal volumes were calibrated using a small-animal ventilator (Minivent, Harvard Apparatus) by injecting $0.1-$ $0.3 \mathrm{ml}$ of air at a rate of $1.5 \mathrm{~Hz}$. $\mathrm{VO}_{2}$ was calculated by subtracting the outflow fraction of $\mathrm{O}_{2}$ from the inflow fraction of $\mathrm{O}_{2}$ and multiplying the difference by the chamber flow rate measured using a gas flowmeter (PV500CCMVADA-CP, Cole-Parmer). Animal temperatures were measured before and after periods of study with j-type thermocouple probes for rectal temperature (BAT-12, Physitemp Instruments) or with telemetric temperature probes (Bio Medic Systems), implanted as described previously (Hodges et al., 2008). Baseline ventilation was recorded at ambient temperatures of $24^{\circ} \mathrm{C}$ (room temperature) or when the plethysmography chamber was warmed to either $27^{\circ} \mathrm{C}$ or $30^{\circ} \mathrm{C}$ using a temper- 
A
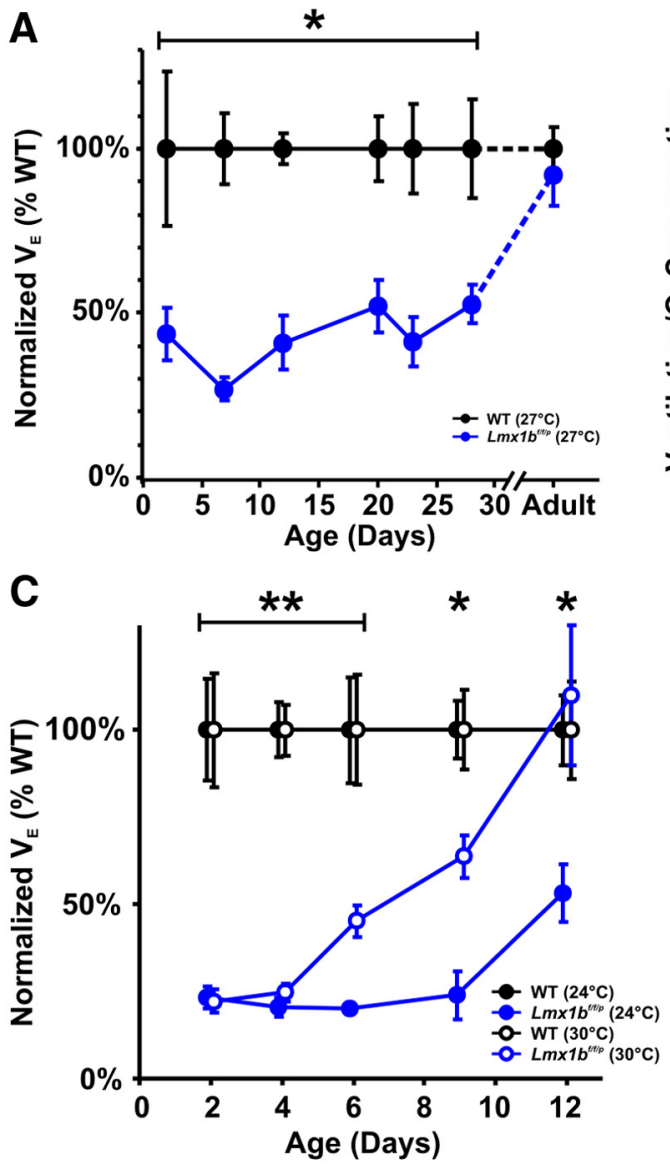

B

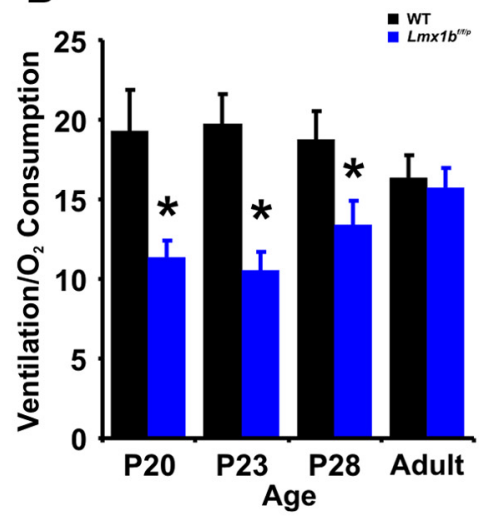

D

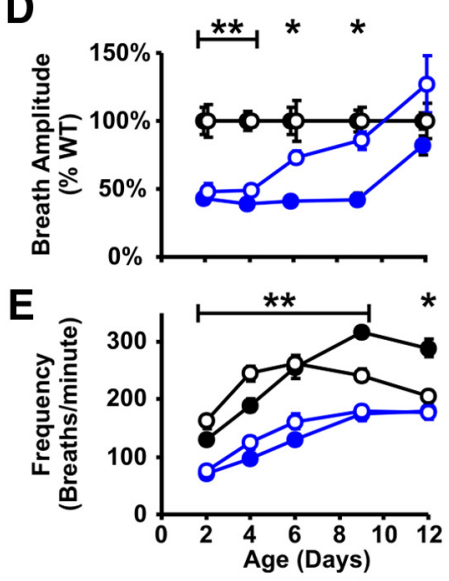

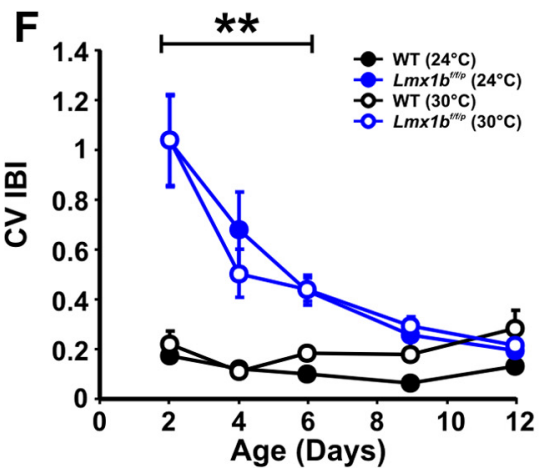

G

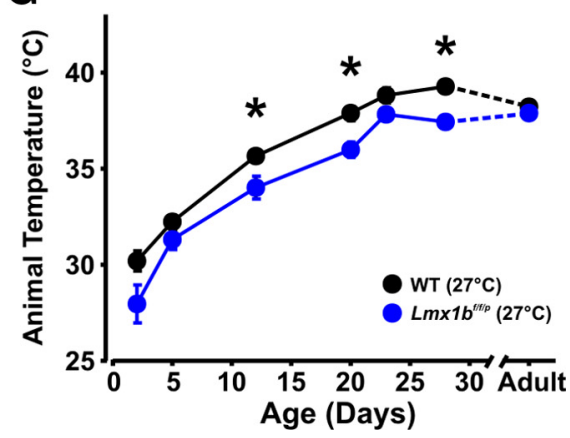

Figure 2. Ventilation is reduced in $L m \times 1 b^{f / f / p}$ mice during postnatal development. $\boldsymbol{A}-\boldsymbol{E}$, Data are presented from two groups of mice: one studied using flow-through plethysmography at $27^{\circ} \boldsymbol{C}(\boldsymbol{A}, \boldsymbol{B})$ and another studied using stop-flow plethysmography at 24 and $30^{\circ} \mathrm{C}(\boldsymbol{C}-\boldsymbol{E})$. $\boldsymbol{A}$, Ventilation, which was normalized to weight and expressed relative to WT mice (black; $n=8-14$ animals per data point), was lower in $L m \times 1 b^{f / f / p}$ mice (blue; $n=5-13$ ) up to the age of P28 $\left({ }^{*} p \leq 0.02\right.$ ), but was normal in adults. $B$, Similarly, the ratio of ventilation to oxygen consumption [calculated in $\mathrm{ml} / \mathrm{min}$ in this case (see Materials and Methods)] was also reduced in $L m \times 1 b^{f f f / p}$ mice $(n=5-6)$ relative to WT mice $(n=8-9)$ from P20 -P28 mice but was normal in adults. ${ }^{*} p \leq 0.045$. C, Ventilation was also reduced ( $\left.p \leq 0.015\right)$ in $L m \times 1 b^{f / f / p}$ mice $(n=6-12)$ compared with WT mice $(n=7-10)$ up to P6 at a warm ambient temperature $\left(30^{\circ} \mathrm{C} ;\right.$ open symbols), and up to $\mathrm{P} 12$ at $24^{\circ} \mathrm{C}$ ( $p \leq 0.014$; solid symbols). $\boldsymbol{D}$, Breath amplitude (normalized to weight and expressed as a percentage of WT value) was lower in $L m \times 1 b^{f / f / p}$ mice up to $\mathrm{P} 4$ at both temperatures $(p \leq 0.006)$ and up to $\mathrm{P} 9$ at $24^{\circ} \mathrm{C}(p<0.001)$. $E$, Breathing frequency was also lower in $L m \times 1 b^{f / f / p}$ mice up to $\mathrm{P} 9$ at both temperatures $(p \leq 0.004)$ and up to $\mathrm{P} 12$ at $24^{\circ} \mathrm{C}(p<0.001)$. ${ }^{*}$ Difference between genotypes at $24^{\circ} \mathrm{C} ;{ }^{* *}$ difference between genotypes at both temperatures. Data points were shifted along the $x$-axis by $\pm 0.2 \mathrm{~d}$ of age in $\boldsymbol{C}$ and $\boldsymbol{D}$ for clarity. Adult data shown here are reproduced from an earlier publication for comparison (Hodges et al., 2008). $\boldsymbol{F}$, Breathing was more irregular in $L m \times 1 b^{f / f / p}$ mice relative to WT mice ${ }^{* *} p<0.05$ ) from $\mathrm{P} 2$ to $\mathrm{P} 6$, as quantified by the $\mathrm{CV} \mathrm{IBI}$ when measured at ambient temperatures of $24^{\circ} \mathrm{C}$ (solid symbols) and $30^{\circ} \mathrm{C}$ (open symbols). G, Animal temperature was slightly lower in $L m \times 1 b^{f / f / p}$ mice relative to WT mice at an ambient temperature of $27^{\circ} \mathrm{C}$ at the ages of $\mathrm{P} 12, \mathrm{P} 20$, and $\left.\mathrm{P} 28{ }^{*} p \leq 0.049\right)$ but was not significantly different at other ages, including adults.

ature controller (TCAT-2AC, Physitemp Instruments) and an incandescent lamp.

Data were continuously acquired with a custom-written data acquisition program written in Matlab (The MathWorks) after digitization using an analog-to-digital converter (PCI-6221, National Instruments). Pressure transducer output was digitized at $100 \mathrm{~Hz}$, and ambient temperature, relative humidity, and $\mathrm{O}_{2}$ concentrations were digitized at $0.1 \mathrm{~Hz}$. Breathing-induced pressure oscillations were analyzed off-line using a custom-written Matlab program that detected peaks and troughs with manual confirmation by the investigator.

En bloc brainstem-spinal cord preparations. En bloc experiments were performed and analyzed by an individual blind to animal genotype, using methods similar to those previously described (Smith et al., 1990). Two-day-old WT and $L m \times 1 b^{f / f / p}$ mice were deeply anesthetized with isoflurane and decapitated, and the brainstem-spinal cord removed and transected at the level of the rostral pons in ice-chilled artificial CSF (aCSF) containing the following (in $\mathrm{mm}): 129 \mathrm{NaCl}, 21 \mathrm{NaHCO}_{3}, 3 \mathrm{KCl}, 1.5 \mathrm{CaCl}_{2}$, $1.0 \mathrm{MgSO}_{4}, 0.58 \mathrm{NaH}_{2} \mathrm{PO}_{4}, 30$ dextrose $(\mathrm{pH}$ 7.35-7.4) after bubbling with $95 \% \mathrm{O}_{2} / 5 \% \mathrm{CO}_{2}$. The preparation was transferred to a recording chamber and superfused with aCSF of the same composition, except that $\mathrm{KCl}$ was increased to 4.5 mм. 1-(2,5-Dimethoxy-4-iodophenyl)-2aminopropane (DOI) hydrochloride $(10 \mu \mathrm{M}$; Sigma-Aldrich) and substance $\mathrm{P}$ acetate salt hydrate $(1 \mu \mathrm{M})$ were dissolved in aCSF and supplied via the superfusate. Bath temperature was maintained at $27-27.5^{\circ} \mathrm{C}$ with a TC-324B temperature controller (Warner Instruments).

Hypoglossal (XII) and cervical (C1-C4) nerve signals were measured via suction electrodes, amplified $(\times 10,000)$, and bandpass filtered $(0.3-1 \mathrm{kHz})$ with a Grass LP511 AC (Astro-med) and DX4-400 differential amplifier (Dagan), and $60 \mathrm{~Hz}$ noise was reduced with a Hum Bug noise eliminator (Quest Scientific). The signal was digitized at $100 \mathrm{~Hz}$ and acquired and analyzed off-line using custom-written software in Matlab. Nerve activity was integrated, and respiratory bursts (onset, peak, and end) detected using a user-defined threshold. The peak of integrated bursts was compared with a baseline value (300 ms before burst onset) to obtain amplitude.

In situ arterially perfused brainstem-spinal cord preparations. Experiments were performed with in situ arterially perfused brainstem-spinal cord preparations from 6- to 8-d-old neonatal rats, which generate patterns of cranial and spinal motoneuron activity similar to those in vivo (Paton, 1996; Dutschmann et al., 2000; Smith et al., 2007). Procedures for setting up the in situ arterially perfused brainstem-spinal cord preparations of neonatal rats (Dutschmann et al., 2000) were as described previously in detail for juvenile rats (Paton, 1996; Smith et al., 2007). In brief, preheparinized (1000 U, i.p.) P6-P8 male Sprague Dawley rats were anesthetized deeply with isoflurane until loss of the paw withdrawal reflex. Rats were bisected subdiaphragmatically, the head and thorax was im- 
mersed in ice-chilled carbogenated Ringer's solution, and the brain was decerebrated precollicularly. Thoracic phrenic (PN) and hypoglossal (XII) nerves were cut distally. Preparations were transferred to a recording chamber. A double lumen cannula (modified DLR-4, Braintree Scientific) was inserted retrogradely into the descending aorta for perfusion. Perfusion solution was supplied via a peristaltic roller pump (Watson Marlow 505D) and consisted of the following (in $\mathrm{mM}$ ): 125 $\mathrm{NaCl}, 24 \mathrm{NaHCO}_{3}, 3 \mathrm{KCl}, 2.5 \mathrm{CaCl}_{2}, 1.25$ $\mathrm{MgSO}_{4}, 1.25 \mathrm{KH}_{2} \mathrm{PO}_{4}, 10$ dextrose (pH 7.357.4) after bubbling with $95 \% \mathrm{O}_{2} / 5 \% \mathrm{CO}_{2}$ at $32^{\circ} \mathrm{C}$. Osmolality was $290 \pm 5 \mathrm{mOsm} \cdot \mathrm{kg}$ $\mathrm{H}_{2} \mathrm{O}^{-1}$. Ficoll $70(1.25 \%)$ was added as an oncotic agent. The second lumen of the cannula was used to monitor aortic perfusion pressure. Vasopressin (200-400 pM as required) was added to the perfusate to raise perfusion pressure to between 70 and $90 \mathrm{~mm} \mathrm{Hg}$ (Pickering and Paton, 2006). Vecuronium bromide $\left(4 \mu \mathrm{g} \cdot \mathrm{ml}^{-1}\right.$; Organon Teknica) was added to the perfusion solution to block neuromuscular transmission. Methysergide maleate (Sigma-Aldrich; dissolved in 10\% DMSO), SR 140333 (SR; a gift from Sanofi-Aventis; dissolved in 7\% ethanol), or MDL 11,939 (MDL; Tocris Bioscience; dissolved in 100\% ethanol) were diluted in the perfusate solution.

Simultaneous PN and XII nerve recordings were obtained with bipolar suction electrodes in situ. All nerve signals were amplified $(\times 5000-10,000)$ and bandpass filtered $(0.3-1 \mathrm{kHz}$ ) with a Cyberamp 360 amplifier (Molecular Devices). Raw recordings were rectified and smoothed by analog or digital integration (30-100 ms time constant) and simultaneously acquired digitally (10 kHz sampling rates) using a PowerLab analog-to-digital converter and Chart v5.0 software (AD Instruments). The parameters describing network population activity (XII and PN inspiratory interburst interval/frequency and burst amplitude) were calculated off-line using Chart v5.0 and Igor Pro (Wavemetrics) software with custom automated analysis procedures and hand checked for accuracy.

Statistics. Statistical significance was tested using $\chi^{2}$ analysis, and group means were compared using a two-sample $t$ test assuming unequal variances when appropriate (Microsoft Excel). One-way or two-way ANOVA was used for comparing effects of genotype, age, temperature, or drug and their interactions, with either Newman-Keuls (Prism 4, GraphPad Software), or Tukey (Systat 11, Systat Software) post hoc analyses for multiple comparisons. The threshold for significance was set to $p<0.05$. All data are presented as mean \pm SEM.

\section{Results}

$L m x 1 b^{f f f / p}$ mice display frequent and severe apnea and high mortality during early development

In contrast to adults (Hodges et al., 2008), neonatal $L m \times 1 b^{f / f / p}$ mice had severely disrupted baseline breathing (Fig. 1A,B). $L m \times 1 b^{f / f / p}$ pups had short trains of low-amplitude, low-frequency breaths interrupted by spontaneous and severe apnea, lasting as long as $55 \mathrm{~s}$ in extreme cases (Fig. 1A). WT pups also occasionally had apnea (defined as an interbreath interval longer than $1 \mathrm{~s}$ ) during the neonatal period. However, apneas in $L m x 1 b^{f / f / p}$ pups were much more frequent, longer, and persisted to a later postnatal age (Fig. $1 B-D)$. At P2, $L m \times 1 b^{f / f / p}$ pups studied at warm ambient temperature $\left(30^{\circ} \mathrm{C}\right)$ spent $39.2 \%$ of the time apneic (calculated as apnea duration ${ }^{\star}$ frequency/total study time), compared with $5.8 \%$ for WT pups (Fig. 1C). Similar results were obtained at an ambient temperature of $24^{\circ} \mathrm{C}$, including the percentage of time apneic (Fig. $1 C$ ), apnea frequency (Fig. $1 C$, inset), and apnea duration (data not shown).

There was even greater disparity between WT and $L m \times 1 b^{f / f / p}$ pups when comparing prolonged apneas $(>5 \mathrm{~s})$. Combining data obtained at ambient temperatures of $24^{\circ} \mathrm{C}$ and $30^{\circ} \mathrm{C}, 100 \%$ of $L m \times 1 b^{f / f / p}$ pups exhibited at least one prolonged apnea when studied for a 5 min period at P2, compared with only $20 \%$ of WT pups (Fig. $1 D$ ). At this age, we observed $1.3 \pm 1.3$ prolonged apneas/h in WT pups, with a mean duration (5.8 $\pm 0.1 \mathrm{~s})$ slightly greater than the defined threshold of $5 \mathrm{~s}$, compared with $52.9 \pm$ 12.5 prolonged apneas/h in $L m \times 1 b^{f / f / p}$ pups (Fig. $1 E$ ), with a mean duration of $9.6 \pm 0.7 \mathrm{~s}$.

Resting ventilation was markedly lower in neonatal $L m \times 1 b^{f / f / p}$ mice compared with WT mice when normalized either to weight (and expressed as a percentage of WT ventilation) or to oxygen consumption (Fig. $2 A-C$ ). This was a consistent finding in multiple datasets collected using different approaches, including flow-through and stop-flow plethysmography (see Materials and Methods), or when measurements were made at different ambient temperatures $\left(24,27\right.$, or $\left.30^{\circ} \mathrm{C}\right)$. The reduced baseline ventilation was because of both a smaller breath amplitude (Fig. 2D) and lower breathing frequency (Fig. 2E). Breathing was also much more irregular in $L m \times 1 b^{f / f / p}$ mice, with the coefficient of variation of the interbreath interval (CV IBI) much greater than WT mice (Fig. 2 F). Animal temperatures were slightly lower in $L m \times 1 b^{f / f / p}$ mice at P12, P20, and P28 (Fig. 2G), consistent with previous observations of a thermoregulatory deficit (Hodges and Richerson, 2008; Hodges et al., 2008). However, the small differences could not explain the marked difference in ventilation between genotypes, and animal temperatures were equal to WT mice at all other ages studied. Most $L m \times 1 b^{f / f / p}$ mice spent very little time breathing with a normal regular (eupneic) pattern, instead often moving air primarily via an erratic pattern (Fig. $1 A$; also see Fig. $6 A$ ) or during vocalization (Fig. $1 B$ ). At P4, vocalization amplitude (normalized to weight) in $L m \times 1 b^{f / f / p}$ mice $[0.0682 \pm 0.005$ arbitrary units (a.u.) $]$ mice was not different compared with WT mice $(0.0706 \pm 0.005$ a.u. $)(p=0.74)$, indicating that the neuromuscular system of $L m \times 1 b^{f / f / p}$ mice was capable of generating large tidal volumes and that our methods were capable of accurately measuring them. Thus, the severe ventilatory phenotype in $L m \times 1 b^{f / f / p}$ mice demonstrates a critical contribution of 5-HT neurons to normal eupneic respiratory output in early development in vivo.

In parallel with the severe respiratory phenotype, many $L m \times 1 b^{f / f / p}$ pups died during the neonatal period. Tail tissue was collected on or before P4 for genotyping from 419 WT and $L m \times 1 b^{f / f / p}$ mice reared at an ambient temperature of $24^{\circ} \mathrm{C}$. The 
A
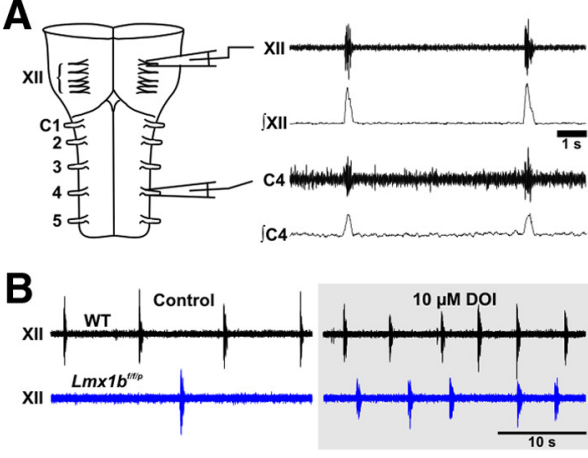

C

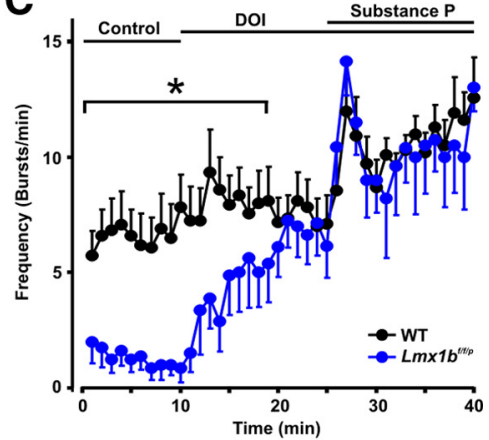

D

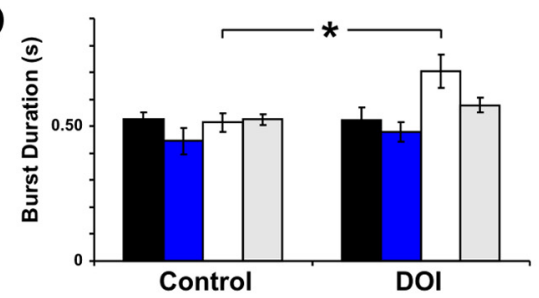

$\mathbf{F}$

Control

XII

XII

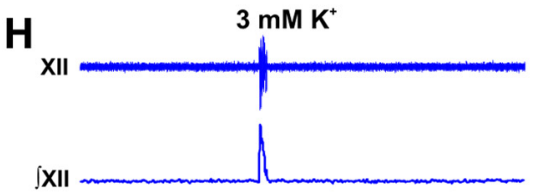

$E_{3}$
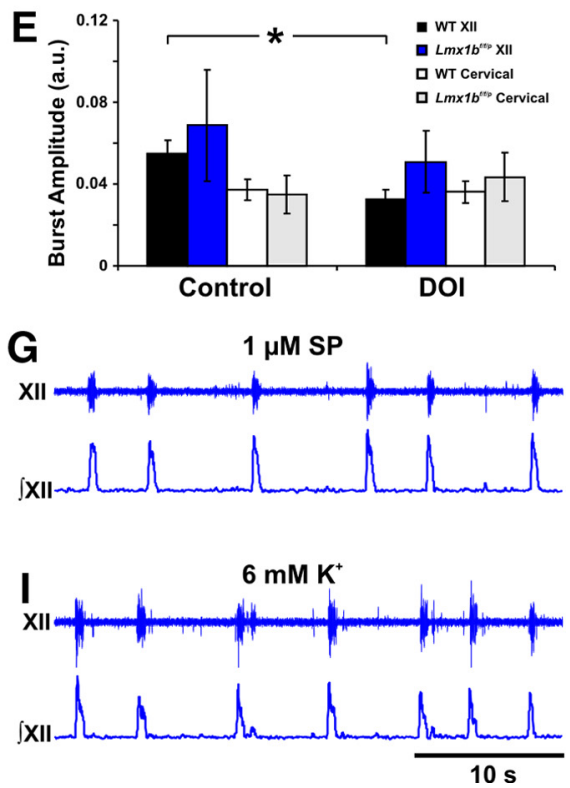

Figure 4. Abnormal breathing in $L m \times 1 b^{f / f / p}$ mice is because of loss of excitatory drive to the respiratory network from central 5-HT neurons. $\boldsymbol{A}$, Raw (first and third traces) and integrated (second and fourth traces) signals from the hypoglossal (XII) and cervical (C1-C4) nerve roots of isolated brainstem-spinal cord (en bloc) preparations from P2 mice showing synchronized inspiratory bursts. $\boldsymbol{B}$, Recordings from XII nerve roots show lower respiratory frequency in $L m \times 1 b^{f f f / p}$ (blue) relative to WT (black) preparations under control conditions (left traces). Respiratory frequency was increased by bath application of DOI (10 $\mu \mathrm{M}$ ) (right

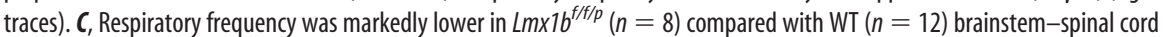
preparations under control conditions ( ${ }^{*} p<0.001$ ). Respiratory burst frequency was significantly increased by DOI in $L m \times 1 b^{f / f / p}$ mice $(p<0.05)$ to a level that was equal to WT preparations during the final $10 \mathrm{~min}$ of application ( $p=0.51)$. Addition of substance $P$ further increased respiratory output in WT and $L m \times 1 b^{f / f / p}$ preparations, with no difference between genotypes $(p=$ 1.0). $\boldsymbol{D}, \boldsymbol{E}$, Hypoglossal (XII) and cervical (C1-C4) nerve burst durations (D) and amplitudes $(\boldsymbol{E})$ were not different between genotypes during the control period or during bath application of $\mathrm{DOI}(p>0.05)$. Cervical nerve burst duration increased ( $p=$ $0.012)$ in $L m \times 1 b^{f / f / p}$ preparations, and XII nerve burst amplitude decreased with DOI compared with control in the WT preparations $(p<0.001)$. * Significant effect of DOI relative to control. $F-I$, Traces of raw XII nerve activity in $L m \times 1 b^{f / f / p}$ preparations during control conditions $(\boldsymbol{F})$, bath application of substance $\mathrm{P}(1 \mu \mathrm{M})(\boldsymbol{G})$, and exposure to $3.0 \mathrm{mM} \mathrm{K}^{+}(\boldsymbol{H})$ or $6.0 \mathrm{mM} \mathrm{K}^{+}(\boldsymbol{I})$.

expected ratio of WT to $L m x 1 b^{f / f / p}$ mice based on a Mendelian pattern of inheritance was $1: 1$, whereas the actual ratio was 234 WT to $185 \mathrm{Lm} \times 1 b^{f / f / p}$ mice $\left(\chi^{2} ; p=0.017\right)$, giving an estimated excess mortality rate of $21 \%$ in $\operatorname{Lm} \times 1 b^{f / f / p}$ mice during the neonatal period.

Apnea, ventilation, and growth rate normalize with increasing age in $L m x 1 b^{f / f / p}$ mice

Some $L m \times 1 b^{f / f / p}$ mice with extremely long apneas as neonates died before reaching adulthood. For example, the P4 $L m \times 1 b^{f / f / p}$ mouse shown in Figure $1 A$ died at P9, and another $L m x 1 b^{f / f / p}$ mouse with severe ( $>55 \mathrm{~s})$ apnea at P6 died at P14. However, the majority of $L m \times 1 b^{f / f / p}$ mice survived beyond P28 despite the prevalence of prolonged apnea in all $L m \times 1 b^{f / f / p}$ mice at P2.

In the $L m \times 1 b^{f / f / p}$ mice that survived the neonatal period, there was marked improvement in all apnea measures with increasing age (Fig. $1 B$ ). The percentage of time apneic, apnea frequency, and apnea duration and percentage of animals exhibiting apnea steadily declined with age in $L m \times 1 b^{f / f / p}$ pups, completely disappearing around P15-P20 (Fig. 1C). In parallel with the reduction in apnea, there was an increase in baseline ventilation and breath amplitude and frequency in $L m \times 1 b^{f / f / p}$ mice. In fact, at P12, ventilation and breath amplitude and frequency of $L m \times 1 b^{f / f / p}$ mice studied at an ambient temperature near thermoneutral $\left(30^{\circ} \mathrm{C}\right)$ was equal to that of WT mice (Fig. $2 C-E$ ). At lower ambient temperature $\left(24^{\circ} \mathrm{C}\right.$ or $27^{\circ} \mathrm{C}$ ), the deficit in minute ventilation and reduced $\mathrm{V}_{\mathrm{E}} / \mathrm{VO}_{2}$ persisted to at least P28 before both measures normalized in adults (Fig. 2A-C). Breathing frequency was lower in $L m \times 1 b^{f / f / p}$ mice throughout development measured at $24^{\circ} \mathrm{C}$ or $27^{\circ} \mathrm{C}$ (Fig. 2E; data not shown), and as shown previously, remained lower in adult $L m \times 1 b^{f / f / p}$ mice (Hodges and Richerson, 2008; Hodges et al., 2008).

In parallel with abnormal respiratory control, there was a lower growth rate in $L m \times 1 b^{f / f / p}$ mice during early development that improved with age. Birth weights were equal for WT and $L m \times 1 b^{f / f / p}$ pups (Fig. 3A, inset), but beginning at $\mathrm{P} 1$, weights were lower in $L m \times 1 b^{f / f / p}$ pups (Fig. $3 A$ ) because of a lower growth rate (Fig. $3 B$ ). Coincident with the time apnea resolved near $\mathrm{P} 15$, there was an increase in growth rate in $L m \times 1 b^{f / f / p}$ mice (Fig. $3 B$ ), leading to normalization of body weight by P55 (Fig. 3A). These results suggest that the initial lag in weight gain was because of growth retardation from hypoxia (Mortola et al., 1990), which presumably resulted from severe apnea.

\section{5-HT and substance $P$ are critical for generation of normal respiratory motor output}

The apnea and hypoventilation in $L m \times 1 b^{f / f / p}$ mice could possibly be because of reduced excitatory serotonergic input to the respiratory network (Pena and Ramirez, 2002; Telgkamp et al., 2002; Ptak et al., 2009), abnormal embryonic development of the respiratory network because of the absence of 5-HT (Bou-Flores et al., 2000), or an indirect influence from abnormalities outside the CNS. To distinguish among these possibilities, we performed recordings from isolated brainstem-spinal cord (en bloc) preparations from P2 WT and $L m \times 1 b^{f / f / p}$ mice (Fig. $4 A$ ). Spontaneous, rhythmic respiratory bursting was present in the hypoglossal (XII) and cervical (C1-C4) nerves of all WT mice (Fig. $4 A, B$ ). In contrast, respiratory output was infrequent (Fig. $4 B$ ) and irregular in $L m \times 1 b^{f / f / p}$ mice. The addition of the $5-\mathrm{HT}_{2 \mathrm{~A}}$ agonist DOI to the superfusate had little effect on burst frequency in WT mice but increased burst frequency in $L m \times 1 b^{f / f / p}$ preparations to that of WT mice (Fig. 4C). There were no differences in burst duration 
or amplitude between genotypes under control conditions or during DOI treatment (Fig. 4D,E). The application of SP [which is colocalized in subpopulations of 5-HT neurons in mice (Holtman et al., 1984; Hokfelt et al., 2000; Ptak et al., 2009)] in combination with DOI significantly increased respiratory burst frequency in both WT and $L m \times 1 b^{f / f / p}$ preparations, with an initial large transient and subsequent smaller sustained increase in frequency (Fig. $4 C$ ). In a different set of $L m \times 1 b^{f / f / p}$ en bloc preparations, we also found that substance P alone (Fig. 4F,G) or 5-HT (data not shown) also increased burst frequency similarly to DOI, whereas increasing $\left[\mathrm{K}^{+}\right]$ to $6 \mathrm{~mm}$, applied to increase respiratory network excitability, caused an increase in frequency that was only transient (Fig. $4 H, I)$. These data show that the reduced respiratory output in $L m \times 1 b^{f / f / p}$ mice is because of a lack of neuromodulatory drive to an intact and functional respiratory network and demonstrate an important role for endogenous central 5-HT and NK-1 receptor activation during early development.

Endogenously released 5-HT and SP are well known to modulate inspiratory network activity in vitro (Pena and Ramirez, 2002; Telgkamp et al., 2002; Ptak et al., 2009), but it has been controversial whether breathing critically depends on these neurotransmitters in the intact CNS (Al-Zubaidy et al., 1996; Toppin et al., 2007). We used P6-P8 rat pups for perfused neonatal brainstem-spinal cord (in situ) preparations, which offer the advantage that they have a more intact nervous system than en bloc in vitro preparations (Richerson and Getting, 1990; Paton, 1996) and allow application of drugs that can cause confounding (e.g., peripheral) effects in vivo. Receptor antagonists were delivered intravascularly via the perfusate to obtain detailed dose-response relationships. 5-HT receptors were blocked with methysergide, a $5-\mathrm{HT}_{1 / 2}$ receptor competitive antagonist that is also a weak partial agonist at $5-\mathrm{HT}_{1 \mathrm{~A} / \mathrm{B} / \mathrm{D}}$ receptors, or $\mathrm{MDL}$, a highly selective $5-\mathrm{HT}_{2 \mathrm{~A}}$ receptor antagonist. $\mathrm{NK}-1$ receptors were blocked by SR. Methysergide progressively reduced the amplitude $(p<0.001)$ and frequency $(p<0.001)$ of inspiratory motor output recorded from $\mathrm{PN}$ and XII nerves over the concentration range tested ( $5-20 \mu \mathrm{M} ; n=3$ ), ultimately eliminating both motor outputs completely in all preparations (data not shown). Similarly, increasing concentrations of MDL also progressively reduced inspiratory burst frequency and amplitude in all preparations $(n=4)$ over the concentration range tested $(5-40 \mu \mathrm{M})$ (Fig. 5A-D) and completely eliminated motor output at the highest MDL concentration $(40 \mu \mathrm{M})$. SR also progressively and significantly reduced inspiratory PN and XII burst frequency and amplitude, eliminating inspiratory motor output in three of four preparations at $40 \mu \mathrm{M}$ and in all preparations at $50 \mu \mathrm{M}$ (Fig. $5 B-D$ ). Thus, as recently shown in mature rats by use of a perfused brain preparation (Ptak et al., 2009) and consistent with the data presented here from neonatal mice lacking 5-HT neurons, neural respiratory output in immature rats is highly dependent on endogenous activation of $5-\mathrm{HT}_{2 \mathrm{~A}}$ and NK-1 receptors.
Normalization of apnea and ventilation in vivo with $5-\mathrm{HT}_{2 \mathrm{~A}}$ receptor activation

Based on these data, we hypothesized that $5-\mathrm{HT}_{2 \mathrm{~A}}$ receptor activation in vivo may improve the frequent and severe apnea observed in $L m \times 1 b^{f f / p}$ mice during early postnatal development. Subcutaneous injections of DOI $(0.1 \mu \mathrm{g} / \mathrm{gm})$ in $L m x 1 b^{f / f / p}$ pups at the age at which apnea is most severe caused significant improvement in apnea indices and resting ventilation (Fig. 6A). One hour after injection, ventilation was 3.1-fold greater, and the percentage of time apneic decreased from $26 \pm 5$ to $10 \pm 3 \%$ (Fig. $6 B)$, a level similar to untreated WT pups at P2 $(6 \pm 2 \%)$. The improvement in ventilation and apnea was sustained for $>4 \mathrm{~h}$ (Fig. 6B). Other measures of ventilatory function were also improved with DOI treatment. Apnea duration $(2.3 \pm 0.4$ vs $1.5 \pm$ $0.1 \mathrm{~s} ; p=0.038)$ and the coefficient of variation of the interbreath interval $(0.90 \pm 0.21$ vs $0.53 \pm 0.06 ; p=0.041)$ both decreased, whereas breathing frequency ( $68.2 \pm 7.0 \mathrm{vs} 127.6 \pm 7.2$ breaths/ min; $p<0.001)$ and breath amplitude $(0.0075 \pm 0.0007$ vs $0.0124 \pm 0.0007$ a.u.; $p=0.016)$ increased $2 \mathrm{~h}$ after DOI injection. Although many aspects of ventilatory dysfunction were improved with systemic DOI treatment, we also observed side effects including tremor and myoclonus. These data suggest that $5-\mathrm{HT}_{2 \mathrm{~A}}$ receptor activation can markedly improve ventilation and apnea in neonatal mice with severe 5-HT system dysfunction but also that an alternative drug or a more targeted application may be necessary to avoid side effects.

\section{Discussion}

This study demonstrates that 5-HT neurons are required for normal respiratory output in vivo during early development. Neonatal mice devoid of central 5-HT neurons displayed frequent and severe apnea, hypoventilation, excess mortality at the time breathing abnormalities were the most severe $(<\mathrm{P} 4)$, and growth 
A

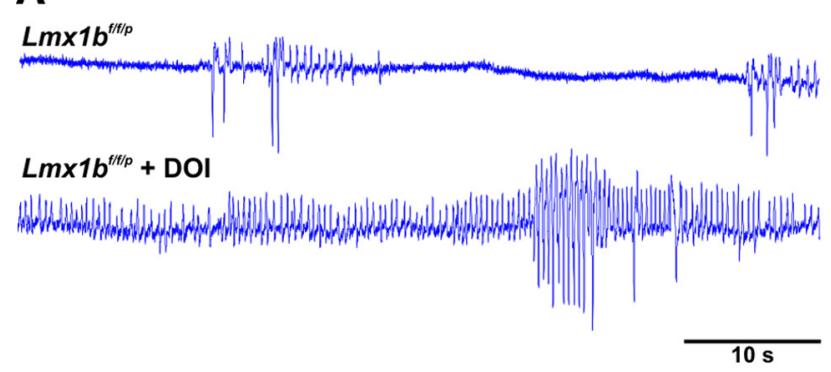

Figure 6. $\quad 5-\mathrm{HT}_{2 \mathrm{~A}}$ receptor stimulation reverses the respiratory defect in neonatal $L m \times 1 b^{f / f / p}$ mice in vivo. A, Plethysmography traces in a P2 $L m \times 1 b^{f f f / p}$ mouse before (top) and $60 \mathrm{~min}$ after (bottom) subcutaneous injection of DOI $(0.1 \mu \mathrm{g} / \mathrm{gm}$ ). $\boldsymbol{B}$, The percentage of time spent apneic decreased ( $p \leq 0.029)$ and relative ventilation increased $(p \leq 0.015)$ in $L m \times 1 b^{f f / p}$ mice $(n=$ 6) for $>4 \mathrm{~h}$ after DOI. * Significant difference between control and DOI treatment in $L m \times 1 b^{f / f / p}$ mice.

retardation. The respiratory dysfunction in $L m \times 1 b^{f / f / p}$ mice was also apparent in vitro, in which it was normalized with $5-\mathrm{HT}_{2 \mathrm{~A}}$ and/or NK-1 receptor activation. Consistent with these results, blockade of endogenous $5-\mathrm{HT}_{2 \mathrm{~A}}$ and/or NK-1 receptor activation eliminated respiratory motor output in neonatal in situ perfused preparations from rats. Importantly, the ventilatory dysfunction and growth retardation in $L m \times 1 b^{f / f / p}$ mice that survived the neonatal period normalized with increasing age, suggesting that either (1) the contributions of 5-HT neurons to baseline ventilation decrease with age or (2) long-term compensation within the respiratory network acts to mitigate effects of 5-HT neuron loss. These data provide clear evidence that the primary influence of 5-HT neurons in respiratory control is excitatory and that they are critical for normal ventilation during early development.

The breathing dysfunction and reduced respiratory output in vivo and in vitro in $L m \times 1 b^{f / f / p}$ mice could theoretically result from either improper network formation because of loss of the trophic effects of 5-HT (Bou-Flores et al., 2000) and/or a lack of excitatory, neuromodulatory drive (Hodges and Richerson, 2008) because of severe depletion of central 5-HT (Zhao et al., 2006) and the cotransmitters SP and thyrotropin-releasing hormone (TRH). However, the data point to the latter possibility, since the respiratory output in en bloc preparations from $L m \times 1 b^{f / f / p}$ mice was normalized with 5-HT, DOI, and substance P. In addition, the improvement of apnea indices and the appearance of rhythmic, eupneic ventilation with a $5-\mathrm{HT}_{2 \mathrm{~A}}$ agonist in vivo suggest that $L m \times 1 b^{f / f / p}$ mice have properly developed a functional respiratory network that simply lacks sufficient excitatory neuromodulatory input. The specific site(s) of action for these neuromodulatory effects is unclear but likely includes the pre-Bötzinger complex and respiratory motor neurons based on previous observations in rhythmic slice preparations (Al-Zubaidy et al., 1996; Pena and Ramirez, 2002; Ptak et al., 2009). The elimination of respiratory network output in situ with selective antagonists for $5-\mathrm{HT}_{2 \mathrm{~A}}$ and NK-1 receptors in neonatal and juvenile preparations (Ptak et al., 2009) further supports this conclusion.

There has been considerable controversy regarding whether 5-HT neurons provide any significant input to the respiratory network in vivo, or whether it is excitatory. Here we show there is a critical dependence of normal breathing on 5-HT neurons during early development. The role and relative importance of 5-HT neurons in adults in vivo remain less clear. Adult $L m \times 1 b^{f / f / p}$ mice exhibit relatively normal, stable eupneic ventilation despite the near-complete lack of 5-HT neurons (Hodges et al., 2008). It is certainly possible that there is only a transient dependence of the
B

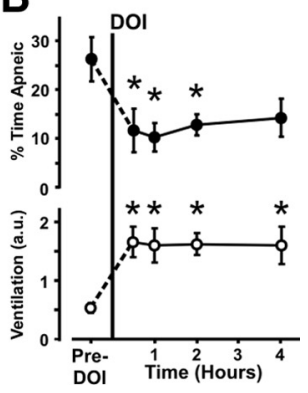

neural respiratory networks on 5-HT and/or substance $\mathrm{P}$ and that these neurons are superfluous or redundant in adults. However, there are alternative interpretations of the existing data, and it remains possible that 5-HT neurons provide essential excitatory input throughout life (Ptak et al., 2009). For example, there is a marked capacity for plasticity in the developing brain, and the normal baseline breathing observed in adult $L m \times 1 b^{f / f / p}$ mice may be a result of compensatory changes that lead to replacement of 5-HT input by an alternative source of excitatory drive. The source of such tonic drive is unknown but may include increased reliance on peripheral chemoreceptors, or other central sources, including medullary (Zanella et al., 2006) or pontine (Hilaire et al., 2004) catecholaminergic neurons. Alternatively, other modes of plasticity could contribute to the ventilatory compensation, such as changes in intrinsic properties of neurons within the respiratory network, as might be expected if the principles of homeostatic plasticity apply to brainstem circuits (Turrigiano and Nelson, 2004).

Previous experiments addressing the issue of the importance of 5-HT neurons for normal respiratory output in adults in vivo are subject to a variety of confounding factors. For example, systemic treatment with 5-HT receptor antagonists does not consistently decrease baseline breathing in vivo or in situ (McGuire et al., 2004; Toppin et al., 2007). Agents that block synthesis of 5-HT cause an increase in breathing (Olson et al., 1979). However, these approaches would have no effect on SP or TRH signaling, both of which are strongly stimulatory to breathing (Cream et al., 1999; Telgkamp et al., 2002; Richerson, 2004). Thus, endogenous release of SP and TRH alone may be sufficient to maintain eupnea after blocking 5-HT receptors (Ptak et al., 2009), and blocking 5 -HT synthesis could actually increase ventilation because of loss of autoinhibition, which could cause greater release of SP and TRH. Lesioning or silencing 5-HT neurons in some cases decreases baseline breathing (Mueller et al., 1984) but in other cases has no effect (Nattie et al., 2004; Cummings et al., 2008). However, it is necessary to use focal injections for these approaches, and it is difficult to influence all 5-HT neurons, since they are so widely distributed throughout the medulla. In addition, symptoms do not usually develop from loss of monoaminergic neurons until a large percentage $(>70-80 \%)$ of them are lost (Blier, 2008). Thus, further work will be needed to define the relative importance of 5-HT neurons for eupnea in adult mammals in vivo.

The work presented here does not address the related question of whether 5-HT neurons are central $\mathrm{CO}_{2}$ chemoreceptors. Significantly more work will be needed to define whether there are changes in the acute responses to hypercapnia or hypoxia in neonatal $L m \times 1 b^{f / f / p}$ mice. Nonetheless, a prerequisite for acidosisstimulated 5-HT neurons to be important as central respiratory $\mathrm{CO}_{2}$ chemoreceptors is that they must provide excitatory input to the respiratory network. The work presented here clearly demonstrates that this is the case, supporting the previous conclusion (Richerson, 2004; Corcoran et al., 2009) that the increase in firing rate of a subset of 5-HT neurons that occurs in response to acidosis both in vitro (Wang et al., 1998, 2001) and in vivo (Larnicol et al., 1994; Veasey et al., 1995; Haxhiu et al., 1996, 2001; Teppema et al., 1997; Okada et al., 2002; Pete et al., 2002; Johnson 
et al., 2005; Kanamaru and Homma, 2007) has the capacity to cause an increase in respiratory output.

Understanding the nature of the role of 5-HT neurons in respiratory control during development has become more important in light of recent findings of multiple 5-HT system abnormalities in sudden infant death syndrome (SIDS) (Paterson et al., 2006; Kinney et al., 2008). Limited physiologic data in infants show episodes of apnea and bradycardia before a SIDS death (Meny et al., 1994; Poets et al., 1999), consistent with the longstanding hypothesis that SIDS is related to a brainstem abnormality in the neuroregulation of cardiorespiratory control (Hunt and Brouillette, 1987). It is not yet known whether the anatomical defects identified in SIDS cases are associated with an increase or a decrease in function of the 5-HT system (Paterson et al., 2006; Kinney et al., 2008), but better defining the roles for 5-HT neurons in control of breathing during development using transgenic animal models (Erickson et al., 2007; Audero et al., 2008; Alenina et al., 2009; Nattie, 2009) may provide insight into how 5-HT neuron defects could lead to pathophysiological changes that cause SIDS.

\section{References}

Alenina N, Kikic D, Todiras M, Mosienko V, Qadri F, Plehm R, Boyé P, Vilianovitch L, Sohr R, Tenner K, Hörtnagl H, Bader M (2009) Growth retardation and altered autonomic control in mice lacking brain serotonin. Proc Natl Acad Sci U S A 106:10332-10337.

Al-Zubaidy ZA, Erickson RL, Greer JJ (1996) Serotonergic and noradrenergic effects on respiratory neural discharge in the medullary slice preparation of neonatal rats. Pflugers Arch 431:942-949.

Audero E, Coppi E, Mlinar B, Rossetti T, Caprioli A, Banchaabouchi MA, Corradetti R, Gross C (2008) Sporadic autonomic dysregulation and death associated with excessive serotonin autoinhibition. Science 321:130-133.

Blier P (2008) Resiliency of monoaminergic systems: the $80 \%$ rule and its relevance to drug development. J Psychopharmacol 22:587-589.

Bou-Flores C, Lajard AM, Monteau R, De Maeyer E, Seif I, Lanoir J, Hilaire G (2000) Abnormal phrenic motoneuron activity and morphology in neonatal monoamine oxidase A-deficient transgenic mice: possible role of a serotonin excess. J Neurosci 20:4646-4656.

Corcoran AE, Hodges MR, Wu Y, Wang W, Wylie CJ, Deneris ES, Richerson GB (2009) Medullary serotonin neurons and central $\mathrm{CO}(2)$ chemoreception. Respir Physiol Neurobiol. Advance online publication. Retrived August 6, 2009. doi:10.1016/j.resp.2009.04.014.

Cream C, Nattie E, Li A (1999) TRH microdialysis into the RTN of the conscious rat increases breathing, metabolism, and temperature. J Appl Physiol 87:673-682.

Cummings K, Commons K, Nattie EE (2008) Destruction of serotonergic neurons in the neonatal rat brainstem decreases breathing and exacerbates apnea-induced bradycardia: evidence for a role for 5-HT signalling in Sudden Infant Death Syndrome (SIDS). Soc Neurosci Abstr 34:383.12/RR79.

Cummings KJ, Commons KG, Fan KC, Li A, Nattie EE (2009) Severe spontaneous bradycardia associated with respiratory disruptions in rat pups with fewer brainstem 5-HT neurons. Am J Physiol Regul Integr Comp Physiol 296:R1783-R1796.

Dutschmann M, Wilson RJ, Paton JF (2000) Respiratory activity in neonatal rats. Auton Neurosci 84:19-29.

Erickson JT, Shafer G, Rossetti MD, Wilson CG, Deneris ES (2007) Arrest of 5HT neuron differentiation delays respiratory maturation and impairs neonatal homeostatic responses to environmental challenges. Respir Physiol Neurobiol 159:85-101.

Günther S, Maroteaux L, Schwarzacher SW (2006) Endogenous 5-HT2B receptor activation regulates neonatal respiratory activity in vitro. J Neurobiol 66:949-961.

Haxhiu MA, Yung K, Erokwu B, Cherniack NS (1996) CO2-induced c-fos expression in the CNS catecholaminergic neurons. Respir Physiol 105:35-45.

Haxhiu MA, Tolentino-Silva F, Pete G, Kc P, Mack SO (2001) Monoaminergic neurons, chemosensation and arousal. Respir Physiol 129:191-209.
Hilaire G, Viemari JC, Coulon P, Simonneau M, Bévengut M (2004) Modulation of the respiratory rhythm generator by the pontine noradrenergic A5 and A6 groups in rodents. Respir Physiol Neurobiol 143:187-197.

Hodges MR, Richerson GB (2008) Contributions of 5-HT neurons to respiratory control: neuromodulatory and trophic effects. Respir Physiol Neurobiol 164:222-232.

Hodges MR, Tattersall GJ, Harris MB, McEvoy SD, Richerson DN, Deneris ES, Johnson RL, Chen ZF, Richerson GB (2008) Defects in breathing and thermoregulation in mice with near-complete absence of central serotonin neurons. J Neurosci 28:2495-2505.

Hökfelt T, Arvidsson U, Cullheim S, Millhorn D, Nicholas AP, Pieribone V, Seroogy K, Ulfhake B (2000) Multiple messengers in descending serotonin neurons: localization and functional implications. J Chem Neuroanat $18: 75-86$

Holtman JR Jr, Norman WP, Skirboll L, Dretchen KL, Cuello C, Visser TJ, Hökfelt T, Gillis RA (1984) Evidence for 5-hydroxytryptamine, substance $\mathrm{P}$, and thyrotropin-releasing hormone in neurons innervating the phrenic motor nucleus. J Neurosci 4:1064-1071.

Hunt CE, Brouillette RT (1987) Sudden infant death syndrome: 1987 perspective. J Pediatr 110:669-678.

Johnson PL, Hollis JH, Moratalla R, Lightman SL, Lowry CA (2005) Acute hypercarbic gas exposure reveals functionally distinct subpopulations of serotonergic neurons in rats. J Psychopharmacol 19:327-341.

Kanamaru M, Homma I (2007) Compensatory airway dilation and additive ventilatory augmentation mediated by dorsomedial medullary 5-hydroxytryptamine 2 receptor activity and hypercapnia. Am J Physiol Regul Integr Comp Physiol 293:R854-R860.

Kinney HC, Richerson GB, Dymecki SM, Darnall RA, Nattie EE (2009) The brainstem and serotonin in the sudden infant death syndrome. Annu Rev Pathol 4:517-550.

Larnicol N, Wallois F, Berquin P, Gros F, Rose D (1994) c-fos-like immunoreactivity in the cat's neuraxis following moderate hypoxia or hypercapnia. J Physiol Paris 88:81-88.

Ling L, Fuller DD, Bach KB, Kinkead R, Olson EB Jr, Mitchell GS (2001) Chronic intermittent hypoxia elicits serotonin-dependent plasticity in the central neural control of breathing. J Neurosci 21:5381-5388.

McGuire M, Zhang Y, White DP, Ling L (2004) Serotonin receptor subtypes required for ventilatory long-term facilitation and its enhancement after chronic intermittent hypoxia in awake rats. Am J Physiol Regul Integr Comp Physiol 286:R334-R341.

Meny RG, Carroll JL, Carbone MT, Kelly DH (1994) Cardiorespiratory recordings from infants dying suddenly and unexpectedly at home. Pediatrics 93:44-49.

Mortola JP, Xu LJ, Lauzon AM (1990) Body growth, lung and heart weight, and DNA content in newborn rats exposed to different levels of chronic hypoxia. Can J Physiol Pharmacol 68:1590-1594.

Mueller RA, Towle AC, Breese GR (1984) Supersensitivity to the respiratory stimulatory effect of TRH in 5,7-dihydroxytryptamine-treated rats. Brain Res 298:370-373.

Nattie E (2009) Sudden infant death syndrome and serotonin: animal models. Bioessays 31:130-133.

Nattie EE, Li A, Richerson G, Lappi DA (2004) Medullary serotonergic neurones and adjacent neurones that express neurokinin-1 receptors are both involved in chemoreception in vivo. J Physiol 556:235-253.

Okada Y, Chen Z, Jiang W, Kuwana S, Eldridge FL (2002) Anatomical arrangement of hypercapnia-activated cells in the superficial ventral medulla of rats. J Appl Physiol 93:427-439.

Olson EB Jr, Dempsey JA, McCrimmon DR (1979) Serotonin and the control of ventilation in awake rats. J Clin Invest 64:689-693.

Paterson DS, Trachtenberg FL, Thompson EG, Belliveau RA, Beggs AH, Darnall R, Chadwick AE, Krous HF, Kinney HC (2006) Multiple serotonergic brainstem abnormalities in sudden infant death syndrome. JAMA 296:2124-2132.

Paton JF (1996) A working heart-brainstem preparation of the mouse. J Neurosci Methods 65:63-68.

Peña F, Ramirez JM (2002) Endogenous activation of serotonin-2A receptors is required for respiratory rhythm generation in vitro. J Neurosci 22:11055-11064.

Pete G, Mack SO, Haxhiu MA, Walbaum S, Gauda EB (2002) CO(2)induced c-Fos expression in brainstem preprotachykinin mRNA containing neurons. Respir Physiol Neurobiol 130:265-274.

Pickering AE, Paton JF (2006) A decerebrate, artificially perfused in situ 
preparation of rat: utility for the study of autonomic and nociceptive processing. J Neurosci Methods 155:260-271.

Poets CF, Meny RG, Chobanian MR, Bonofiglo RE (1999) Gasping and other cardiorespiratory patterns during sudden infant deaths. Pediatr Res 45:350-354.

Ptak K, Yamanishi T, Aungst J, Milescu LS, Zhang R, Richerson GB, Smith JC (2009) Raphé neurons stimulate respiratory circuit activity by multiple mechanisms via endogenously released serotonin and substance P. J Neurosci 29:3720-3737.

Richerson GB (2004) Serotonergic neurons as carbon dioxide sensors that maintain $\mathrm{pH}$ homeostasis. Nat Rev Neurosci 5:449-461.

Richerson GB, Getting PA (1990) Preservation of integrative function in a perfused guinea pig brain. Brain Res 517:7-18.

Smith JC, Greer JJ, Liu GS, Feldman JL (1990) Neural mechanisms generating respiratory pattern in mammalian brain stem-spinal cord in vitro. I. Spatiotemporal patterns of motor and medullary neuron activity. J Neurophysiol 64:1149-1169.

Smith JC, Ellenberger HH, Ballanyi K, Richter DW, Feldman JL (1991) PreBotzinger complex: a brainstem region that may generate respiratory rhythm in mammals. Science 254:726-729.

Smith JC, Abdala AP, Koizumi H, Rybak IA, Paton JF (2007) Spatial and functional architecture of the mammalian brainstem respiratory network: a hierarchy of three oscillatory mechanisms. J Neurophysiol 98:3370-3387.

Telgkamp P, Cao YQ, Basbaum AI, Ramirez JM (2002) Long-term deprivation of substance P in PPT-A mutant mice alters the anoxic response of the isolated respiratory network. J Neurophysiol 88:206-213.
Teppema LJ, Veening JG, Kranenburg A, Dahan A, Berkenbosch A, Olievier C (1997) Expression of c-fos in the rat brainstem after exposure to hypoxia and to normoxic and hyperoxic hypercapnia. J Comp Neurol 388:169-190.

Toppin VA, Harris MB, Kober AM, Leiter JC, St-John WM (2007) Persistence of eupnea and gasping following blockade of both serotonin type 1 and 2 receptors in the in situ juvenile rat preparation. J Appl Physiol 103:220-227.

Turrigiano GG, Nelson SB (2004) Homeostatic plasticity in the developing nervous system. Nat Rev Neurosci 5:97-107.

Veasey SC, Fornal CA, Metzler CW, Jacobs BL (1995) Response of serotonergic caudal raphe neurons in relation to specific motor activities in freely moving cats. J Neurosci 15:5346-5359.

Wang W, Pizzonia JH, Richerson GB (1998) Chemosensitivity of rat medullary raphe neurones in primary tissue culture. J Physiol 511:433-450.

Wang W, Tiwari JK, Bradley SR, Zaykin RV, Richerson GB (2001) Acidosisstimulated neurons of the medullary raphe are serotonergic. J Neurophysiol 85:2224-2235.

Zanella S, Roux JC, Viemari JC, Hilaire G (2006) Possible modulation of the mouse respiratory rhythm generator by A1/C1 neurones. Respir Physiol Neurobiol 153:126-138.

Zhao ZQ, Scott M, Chiechio S, Wang JS, Renner KJ, Gereau RW 4th, Johnson RL, Deneris ES, Chen ZF (2006) Lmxlb is required for maintenance of central serotonergic neurons and mice lacking central serotonergic system exhibit normal locomotor activity. J Neurosci 26:12781-12788. 